\title{
Reduction of common mode voltage for cascaded multilevel inverters using phase shift keying technique
}

\author{
Vinh-Quan Nguyen, Quang-Tho Tran \\ Faculty of Electrical and Electronics Engineering, HCM City University of Technology and Education, Vietnam
}

\begin{tabular}{l} 
Article Info \\
\hline Article history: \\
Received Jun 15, 2020 \\
Revised Aug 11, 2020 \\
Accepted Aug 21, 2020 \\
\hline
\end{tabular}

\section{Keywords:}

Carrier wave modulation

Cascaded multilevel inverter

Common mode voltage

Phase shift keying

Total harmonic distortion

\begin{abstract}
Demand of cascaded multilevel inverters in industries of electric drives and renewable energy is increasing due to their large-scale capacity and high voltage. The modulation technique of inverters significantly affects the power quality of the inverter output voltage. This paper proposes a new method of carrier wave modulation using the phase shift keying technique for cascaded multilevel inverters. The phase of a constant frequency carrier wave is changed at an accurate time by an input sinusoidal control signal. This modulation technique is simply implemented and only needs a small memory. It also helps reduce the common mode voltage of inverters in order to suppress the output voltage harmonics. Moreover, the ability to reduce switching count also helps the inverters decrease switching loss. The simulated and experienced results on a cascaded 9-level 3-phase inverter and an F28379D DSP kit have validated the performance of the proposed technique compared with that of the APOD and POD methods.
\end{abstract}

This is an open access article under the CC BY-SA license.

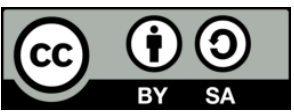

\section{Corresponding Author:}

Quang-Tho Tran

Faculty of Electrical and Electronics Engineering

HCM City University of Technology and Education, Vietnam

Email: thotq@hcmute.edu.vn

\section{INTRODUCTION}

Demand of cascaded multilevel inverters is increasing [1-8] in industries of electric drives and renewable energy $[4,9,10]$ due to their benefits such as large-scale capacity, the ability to provide a sinusoidal shaped output voltage [11], and suppress $\mathrm{dv} / \mathrm{dt}$. The modulation technique significantly affects the power quality of the inverter output voltage. There have been many modulation solutions published, in most these solutions, the control signals are compared directly with the carrier waves that have not been modulated [12-16]. Due to the independence between the carrier wave and the control signal, this makes the carrier wave not contain information of any quantities. Thus, the reconstructing of the control signal in output voltage is very difficult to gain the results as expected. Therefore, the appearance of common mode (CM) voltage in the inverters cannot be avoided. There are many solutions [17-24] to improve the output power quality of inverters by using the reduced-common-mode voltage strategies. However, the increase of carrier wave frequency makes the memory size and switching count increase. This also causes the voltage harmonics and the switching loss to increase. Moreover, the limits of hardware in the fact make these solutions be difficult to implement due to higher expenditures.

The phase shift keying technique (PSK) has been used extensively in telecommunication [25-28], but it has never been used in inverters. PSK is a digital process of modulation which conveys information data of a control signal by modulating the phase of a constant frequency carrier wave. This paper proposes a method for carrier wave modulation of cascaded multilevel inverters using the phase shift keying technique. The PSK of carrier waves in every fundamental period helps the switching of the switches become more 
optimal in every voltage level. As a result, the advantages of the proposed method help reduce the common mode voltage and improve the power quality of inverter output voltage. In addition, the results of the proposed method are also compared with those of the alternative phase opposition disposition (APOD) and phase opposition disposition (POD) techniques. The performance has also been validated by relying on the results of simulation and experiment on a cascaded 9-level inverter system and an F28379D DSP kit for balanced and unbalanced DC sources. A cascaded 9-level inverter model is showed in Section 2. The phase modulation carrier wave of the proposed method is presented in Section 3. Section 4 shows the simulation and experiment results and discussions for the PSK, APOD and POD methods to validate the performance of the proposed method. The benefits of modulated carrier waves are also concluded in Section 5.

\section{CASCADED 9-LEVEL INVERTER SYSTEM}

The one-phase structure of a cascaded 9-level H-bridge 3-phase inverter is presented in Figure 1. Where $S_{j x}$ is the state ON/OFF for the upper switches respectively as (1), with the phase $x=a, b, c$. The lower switches are symbolized as $\mathrm{S}_{\mathrm{jx}}$. Each phase terminal of inverter is connected with an inductor $\mathrm{L}$ as $50 \mathrm{mH}$ and a load resistor $\mathrm{R}$ as $45 \Omega$. The voltage of each DC source is $30 \mathrm{~V}$.

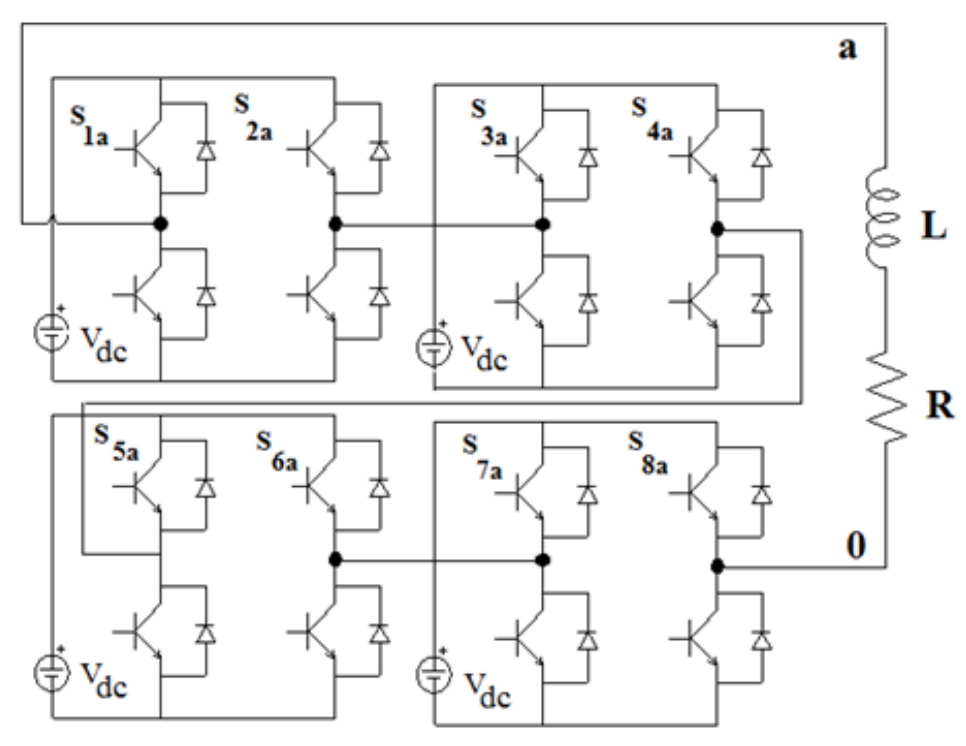

Figure 1. Phase A of a cascaded 9-level H-bridge 3-phase inverter

$$
\text { Where: } S_{j a}+S_{j a}^{\prime}=1 ; \quad \text { with } j=1 \div 8
$$

Table 1 describes the switching states of switches for phase A. Where $n=9$ is the level number of the inverter and the dc voltage sources are the same, 9 levels of output voltage are $-4 \mathrm{~V}_{\mathrm{dc}},-3 \mathrm{~V}_{\mathrm{dc}},-2 \mathrm{~V}_{\mathrm{dc}},-1 \mathrm{~V}_{\mathrm{dc}}, 0$, $+1 \mathrm{~V}_{\mathrm{dc}},+2 \mathrm{~V}_{\mathrm{dc}},+3 \mathrm{~V}_{\mathrm{dc}}$, and $+4 \mathrm{~V}_{\mathrm{dc}}$ respectively. In the inverter control diagram showed in Figure 2 , $\mathrm{g}(\mathrm{t})$ is the control signal with the magnitude from -1 to $+1, \mathrm{G}(\mathrm{t})$ is the signal normalized appropriate to the number of levels for inverter and given in (2).

Table 1. The switching state of switches for phase A

\begin{tabular}{cccccccccc}
\hline $\mathrm{n}$ & $\mathrm{S}_{1 \mathrm{a}}$ & $\mathrm{S}_{2 \mathrm{a}}$ & $\mathrm{S}_{3 \mathrm{a}}$ & $\mathrm{S}_{4 \mathrm{a}}$ & $\mathrm{S}_{5 \mathrm{a}}$ & $\mathrm{S}_{6 \mathrm{a}}$ & $\mathrm{S}_{7 \mathrm{a}}$ & $\mathrm{S}_{8 \mathrm{a}}$ & Output voltage \\
\hline 0 & 0 & 1 & 0 & 1 & 0 & 1 & 0 & 1 & $-4 \mathrm{~V}_{\mathrm{dc}}$ \\
1 & 0 & 1 & 0 & 1 & 0 & 1 & 0 & 0 & $-3 \mathrm{~V}_{\mathrm{dc}}$ \\
2 & 0 & 1 & 0 & 1 & 0 & 0 & 0 & 0 & $-2 \mathrm{~V}_{\mathrm{dc}}$ \\
3 & 0 & 1 & 0 & 0 & 0 & 0 & 0 & 0 & $-1 \mathrm{~V}_{\mathrm{dc}}$ \\
4 & 0 & 0 & 0 & 0 & 0 & 0 & 0 & 0 & $0 \mathrm{~V}_{\mathrm{dc}}$ \\
5 & 1 & 0 & 0 & 0 & 0 & 0 & 0 & 0 & $+1 \mathrm{~V}_{\mathrm{dc}}$ \\
6 & 1 & 0 & 1 & 0 & 0 & 0 & 0 & 0 & $+2 \mathrm{~V}_{\mathrm{dc}}$ \\
7 & 1 & 0 & 1 & 0 & 1 & 0 & 0 & 0 & $+3 \mathrm{~V}_{\mathrm{dc}}$ \\
8 & 1 & 0 & 1 & 0 & 1 & 0 & 1 & 0 & $+4 \mathrm{~V}_{\mathrm{dc}}$ \\
\hline
\end{tabular}




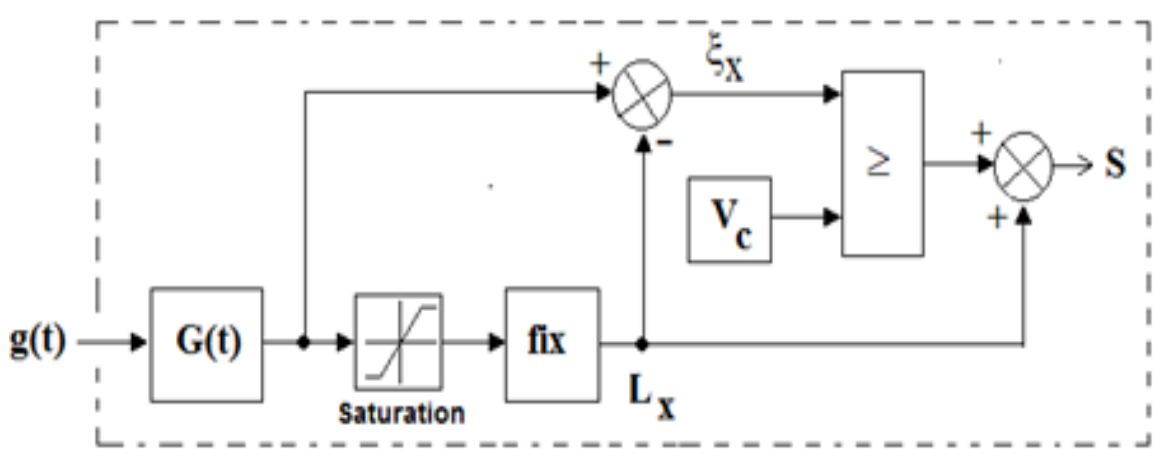

Figure 2. Control diagram of the inverter

$$
G(t)=(g(t)+1) \frac{\mathrm{n}-1}{2}
$$

In the control model for the cascaded inverter, two components of the voltage $G(t)$ are $\xi_{x}$ and $L_{x}$ $(x=a, b, c)$. Where $0 \leq L_{x} \leq n-2$ is the integer of the signal $G(t)$ and given by (3).

$$
L_{X}\left\{\begin{array}{l}
n-2, \text { if } G(t) \geq n-2 \\
f i x(G(t)), \text { otherwise }
\end{array}\right.
$$

And $0 \leq \xi_{x} \leq 1$ is the remainder after division and given by (4).

$$
\xi_{x}=G(t)-L_{x}
$$

\section{THE PROPOSED CARRIER WAVE PHASE MODULATION}

The carrier wave is described as (5).

$$
e(t)=A_{c} \cos \left(\omega_{c} t+\theta\right)
$$

The carrier wave before normalization has a form as (6) in Figure 3 . Where $\omega_{c}$ is as $2 \pi f_{c}$ and $\theta$ is the phase angle.

$$
c(t)=\frac{2}{\pi} \sin ^{-1}(e(t))=\frac{2}{\pi} \sin ^{-1}\left(A_{c} \cos \left(\omega_{c} t+\theta\right)\right)
$$

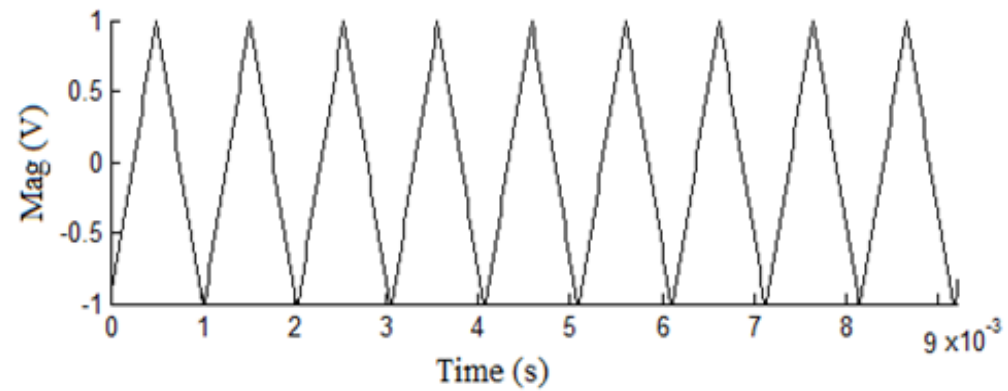

Figure 3. Carrier wave $\mathrm{c}(\mathrm{t})$ before normalization with $\mathrm{Ac}=1$ and $\mathrm{f}_{\mathrm{c}}=1 \mathrm{kHz}$

The carrier wave has been normalized by (7) and showed in Figure 4. Where $\max (\mathrm{c}(\mathrm{t}))$ and $\min (\mathrm{c}(\mathrm{t}))$ are the maximum and minimum magnitudes of $\mathrm{c}(\mathrm{t})$ respectively. The spectrum of unmodulated carrier wave in Figure 5 shows the magnitude as 0.4 at the frequency of $1 \mathrm{kHz}$ and its THD as $10.51 \%$. 
$V_{c}(t)=\frac{\max (c(t))+c(t)}{\max (c(t))+\min (c(t))}$

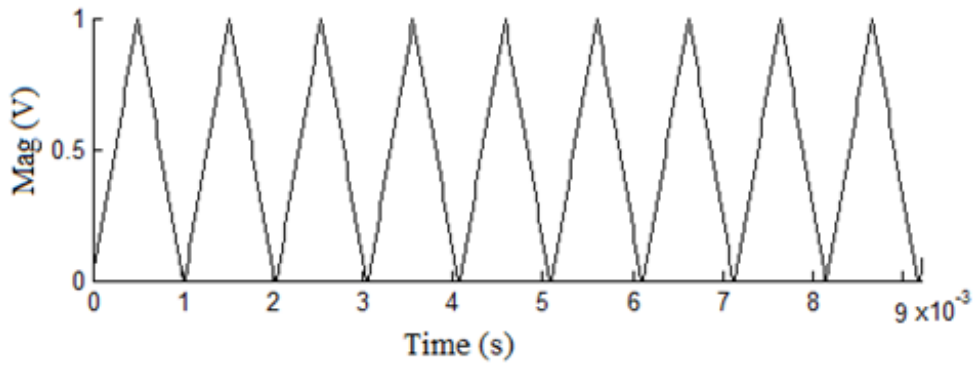

Figure 4. Normalized carrier waves

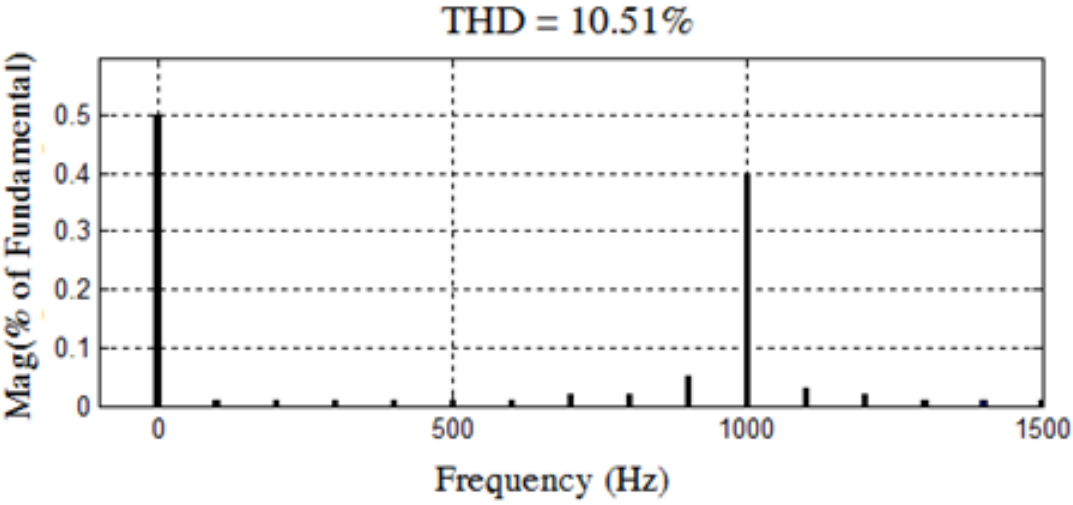

Figure 5. Carrier spectrum before modulation

This showed that the carrier wave before modulation is completely independent from the control signal. Thus, it is very difficult to reconstruct the control signal basing on such carrier waves. This leads to producing the common mode voltage (CMV) and output voltage harmonics.

\subsection{The proposed phase shift keying technique}

A sinusoidal control signal as (8) is used to modulate the phase of carrier wave.

$g(t)=E_{m} \sin \left(\omega_{m} t\right)$

The PSK modulated waveform can be in phase or opposite phase with the control signal $\mathrm{g}(\mathrm{t})$. This waveform is also described as (9)

$c_{\mathrm{PSK}}(t)=\mathrm{A} \cdot \mathrm{d}(t) \cdot \mathrm{c}(t)$

Where $\mathrm{A}= \pm 1$ is the magnitude of the high frequency carrier wave, $\mathrm{c}(\mathrm{t})$, and $\mathrm{d}(\mathrm{t})= \pm 1$ depends on the control signal.

$d(t)=\left\{\begin{array}{l}+1 \text { for } g(t) \geq 0 \\ -1 \text { for } g(t)<0\end{array}\right.$

Figure 6 is the waveform of $\mathrm{d}(\mathrm{t})$ with the magnitude of \pm 1 . It also is a function of the control signal $\mathrm{g}(\mathrm{t})$ and the PSK modulated carrier wave. The normalized carrier wave can be obtained from (7) as follows:

$$
V_{\mathrm{PSK}}(t)=\frac{\max +c_{\mathrm{PSK}}(t)}{\max +\min }
$$


The PSK modulated carrier wave $\mathrm{V}_{\mathrm{PSK}}(\mathrm{t})$ with the frequency of $1 \mathrm{KHz}$ is shown in Figure 7 . The spectrum of this carrier wave is also shown in Figure 8 with the magnitude of 0.42 at the frequency of $1 \mathrm{kHz}$ and THD as $12.17 \%$.
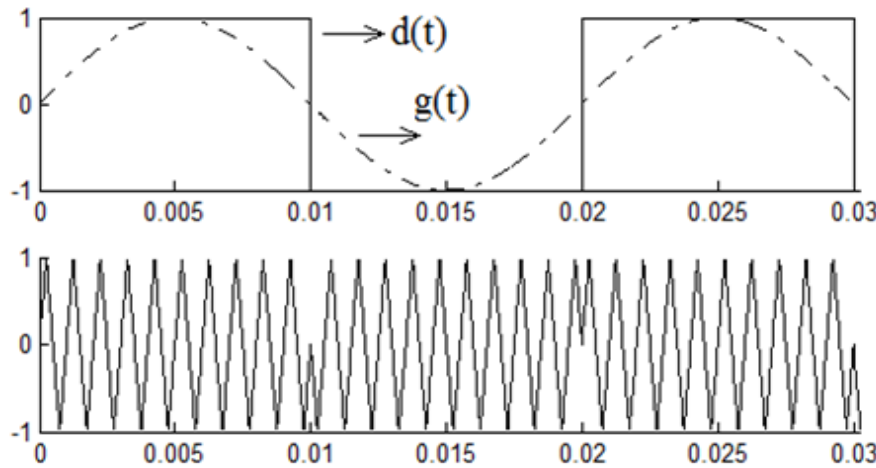

Figure 6. PSK modulated carrier waves

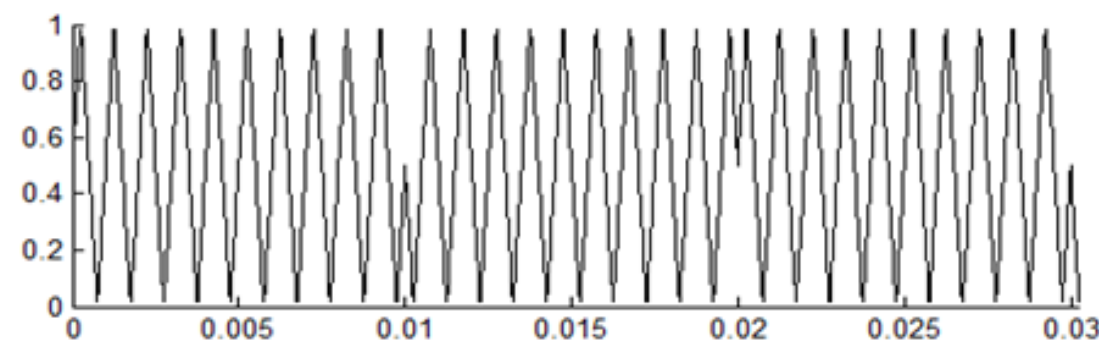

Figure 7. Normalized PSK carrier waves of one phase

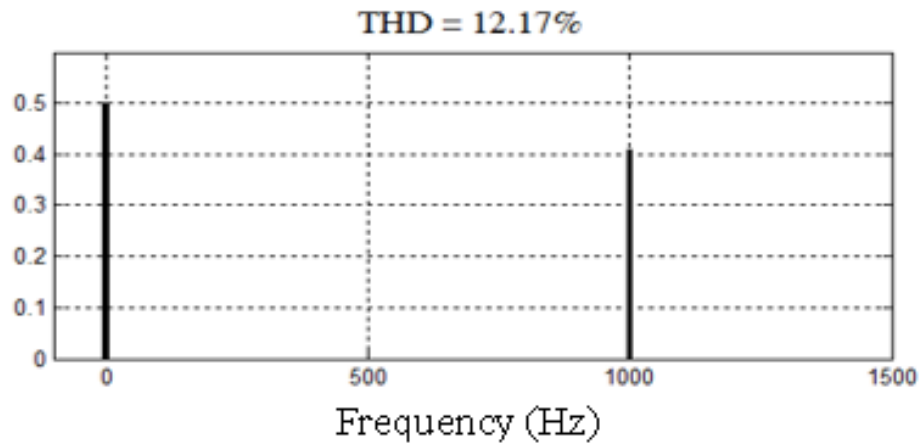

Figure 8. Spectrum of PSK carrier waves

The common mode voltage of the unmodulated carrier waves in Figure 9 (a) is $\pm 2 V_{d c} / 3$ for $E_{m}=1$, twice higher than that of the PSK method in Figure 9(b) and satisfied (12).

$$
V_{\mathrm{CM}}=\frac{\mathrm{Vao}+\mathrm{Vbo}+\mathrm{Vco}}{3}
$$

Basing on Figure 9 and (12), at the specific moment t, the common mode voltage for the unmodulated carrier waves in Figure 9 (a) is $+20 \mathrm{~V}$ (as $2 * \mathrm{~V}_{\mathrm{dc}} / 3$ ) while that of the modulated ones using PSK in Figure $9(\mathrm{~b})$ is $+10 \mathrm{~V}$ (as $1 * \mathrm{~V}_{\mathrm{dc}} / 3$ ). The phase shift of carrier waves in every fundamental period helps the switching state change more optimal and reduce the common mode voltage.

Reduction of common mode voltage for cascaded multilevel inverters using phase ... (Vinh-Quan Nguyen) 


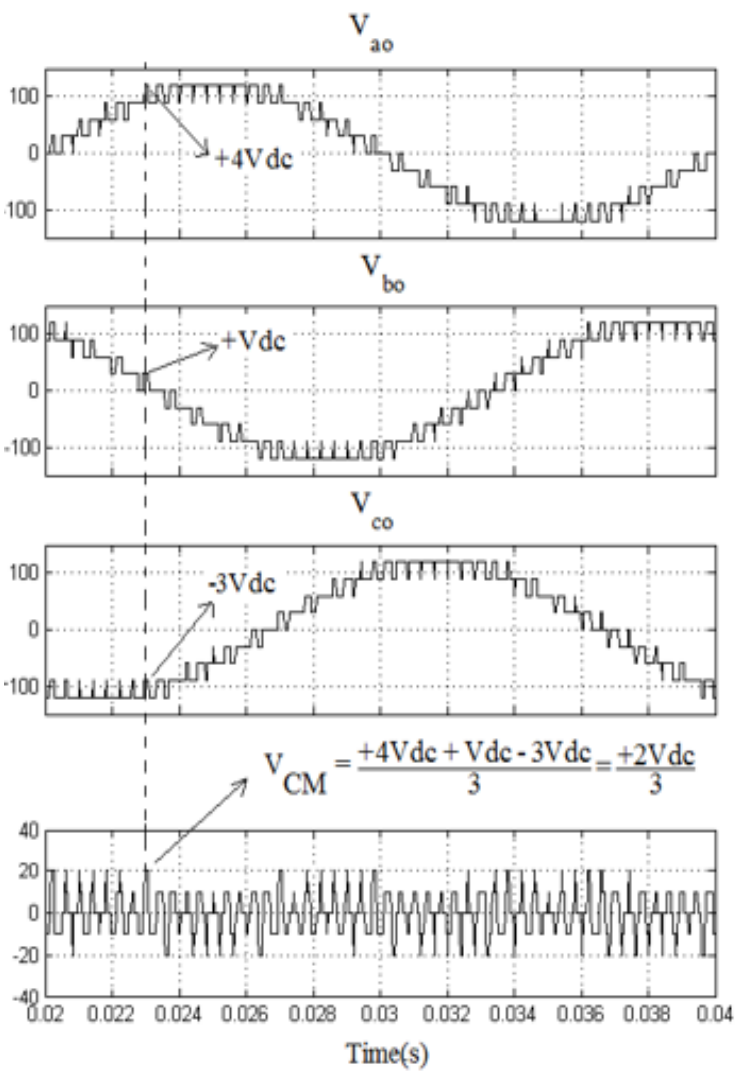

(a) CMV of the unmodulated carrier waves

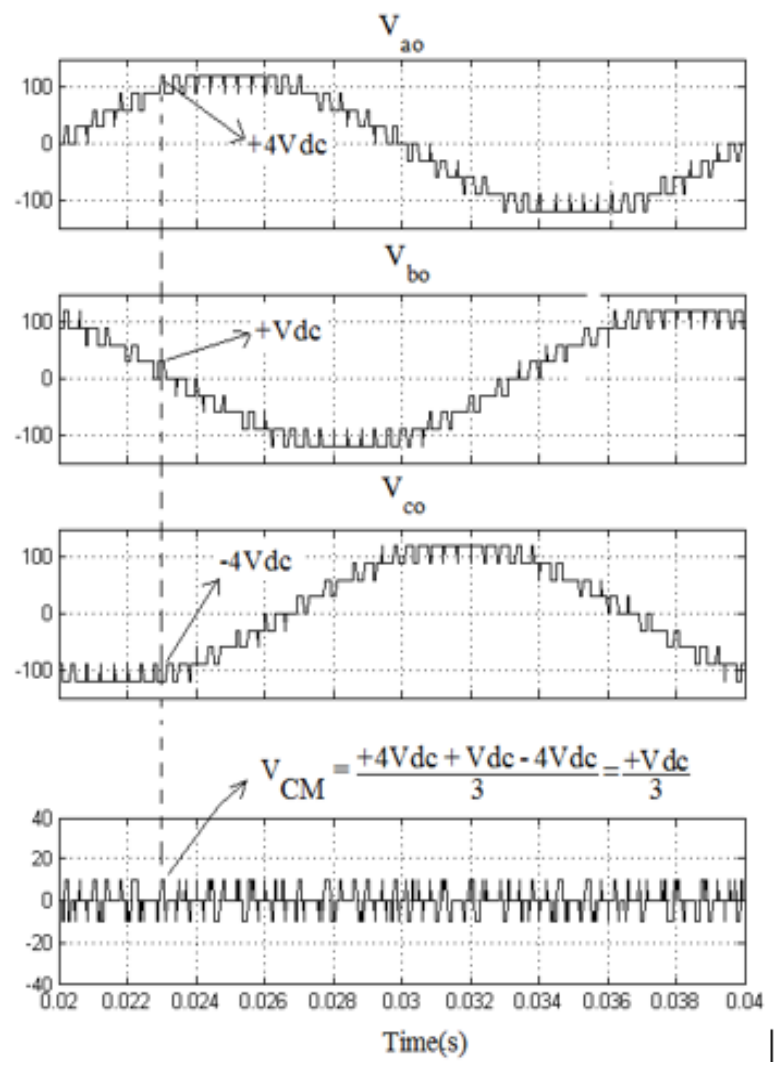

(b) CMV of the PSK modulated carrier waves

Figure 9. Phase voltages and common mode voltages

\subsection{Strategy for reducing the number of switching commutations}

In order to enhance the performance of the PSK method much more, an offset function $\xi_{\mathrm{o}}$ is also proposed to add $\xi_{x}$ in this paper as (13). Where $n=9$ is the level of inverter and $F_{L}$ is as (14). When using the proposed strategy in Figure 10, the number of switching commutations in one fundamental period is also decreased and showed in Section 4.

$$
\xi_{o}=\left\{\begin{array}{l}
1-\max \left(\xi_{x}\right), \text { if } F_{L}=\frac{3(\mathrm{n}-1)}{2}-2 \\
-\min \left(\xi_{x}\right), \text { if } F_{L}=\frac{3(\mathrm{n}-1)}{2}-1 \\
0, \text { otherwise }
\end{array}\right.
$$

$\mathrm{F}_{\mathrm{L}}=\sum \mathrm{L}_{\mathrm{x}}, \mathrm{x}=\mathrm{a}, \mathrm{b}, \mathrm{c}$

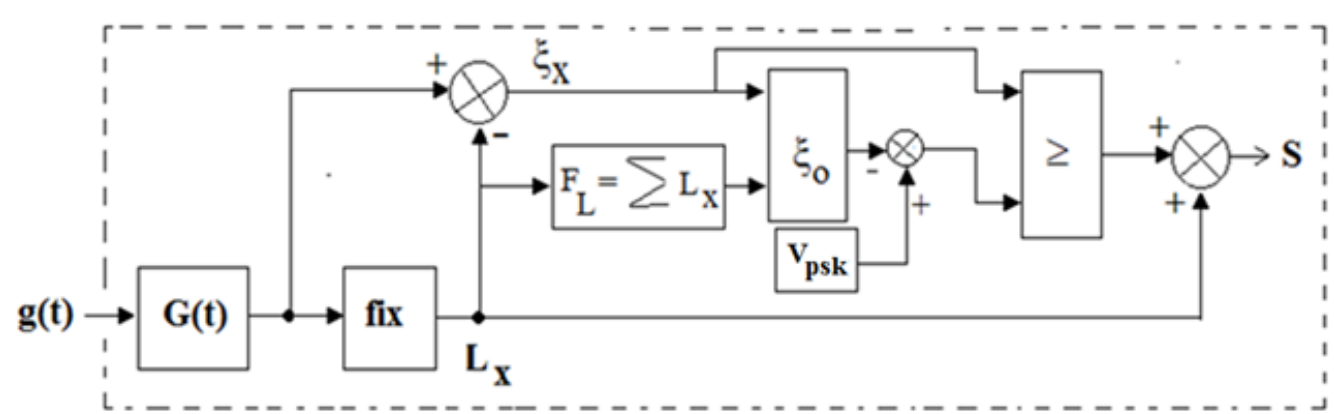

Figure 10. Proposed strategy for reducing the number of switching commutations 


\section{SIMULATION AND EXPERIMENT RESULTS}

The parameters for simulation and experiment system are showed in Table 2. Three magnitude values of $\mathrm{E}_{\mathrm{m}}$ as $1,0.5$, and 0.2 are used to test in this paper for validating the wide range of modulation index.

Table 2. System parameters

\begin{tabular}{cc}
\hline Description & Value \\
\hline Inductor L & $50 \mathrm{mH}$ \\
Load resistor R & $45 \Omega$ \\
Sample time Ts & $20 \mu \mathrm{s}$ \\
Carrier frequency & $2.5 \mathrm{kHz}$ \\
Deadtime & $2 \mu \mathrm{s}$ \\
$\mathrm{V}_{\mathrm{dc}}$ & $30 \mathrm{~V}$ \\
\hline
\end{tabular}

\subsection{Simulation results}

The simulation diagram using PSK technique is showed in Figure 11. Where the inductor $\mathrm{L}$ is $50 \mathrm{mH}$ and the load resistor is $45 \Omega$. The simulation results of the PSK, APOD, and POD methods are also shown in Figure 12, Figure 13, Figure 14, Figure 15, Figure 16, and Figure 17 for the different magnitude values of $E_{m}$.

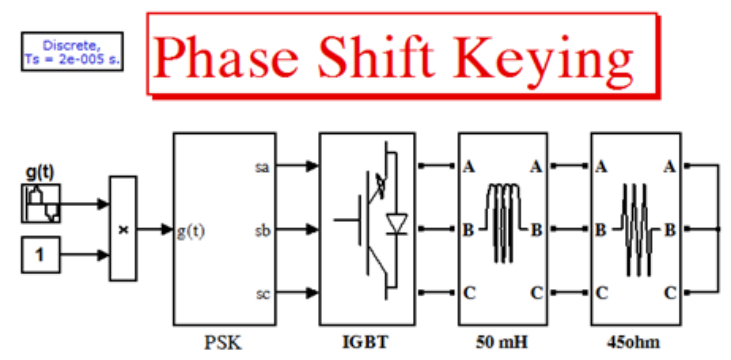

Figure 11. Simulation diagram of PSK modulation

In case $E_{m}=1$, the $C M$ voltages of the PSK and POD are as $\pm V_{d c} / 3$ in Figures 12 (a) and 12(c) while that of the APOD in Figure 12(b) is as $\pm 2 \mathrm{~V}_{\mathrm{dc}} / 3$. In addition, the line voltage THD value of the PSK, as $9.36 \%$, is lower than those of the APOD and POD methods as $12.5 \%$ and $12 \%$ respectively. This helps the phase current THD value of the PSK method in Figure 13(a), as $0.6 \%$, smaller than those the APOD and POD in Figures 13(b) and 13(c), as $0.67 \%$ and $0.7 \%$ respectively.
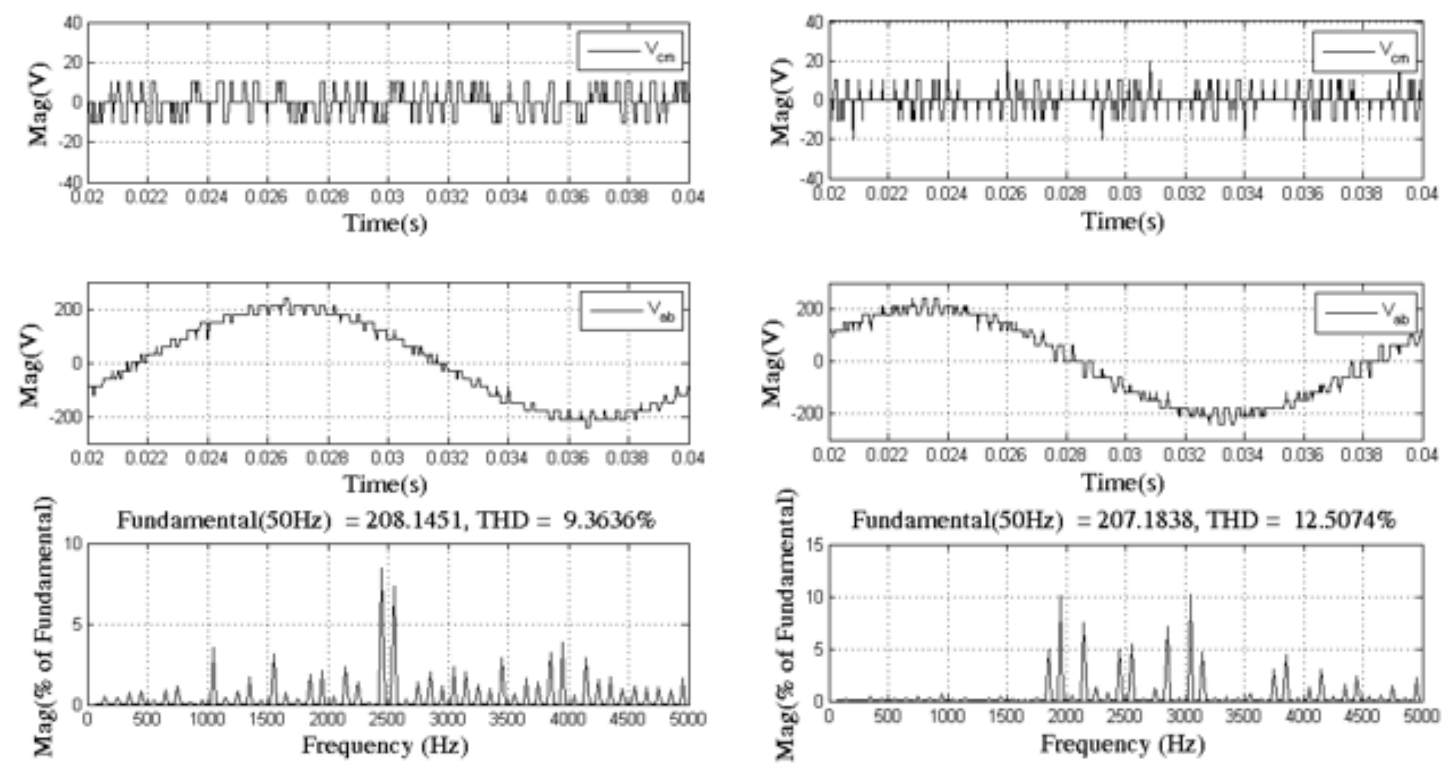

(a) PSK modulation strategy

(b) APOD

Reduction of common mode voltage for cascaded multilevel inverters using phase... (Vinh-Quan Nguyen) 

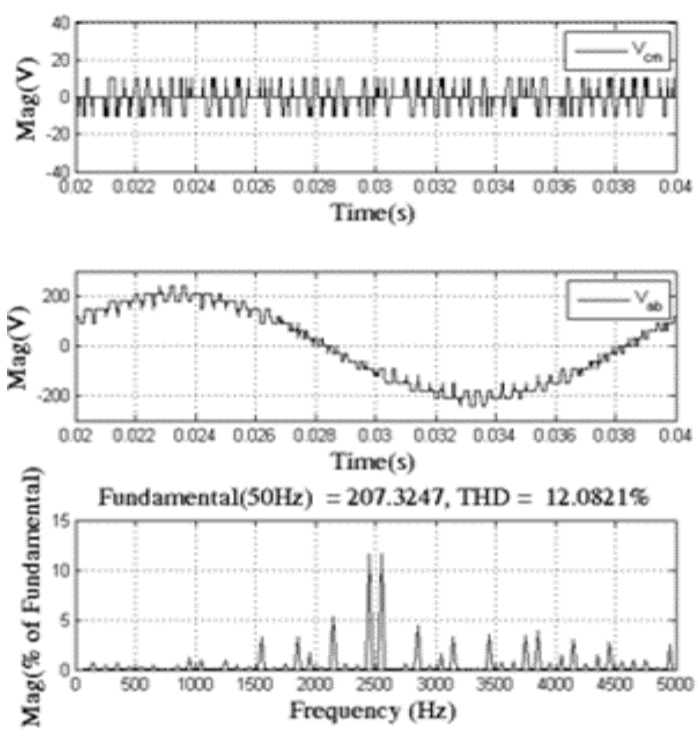

(c) POD

Figure 12. Top Trace: CMV waveform, Middle Trace: Line voltage $\mathrm{V}_{\mathrm{ab}}$, Bottom Trace:

THD of line voltage $V_{a b}$ for $E_{m}=1.0$
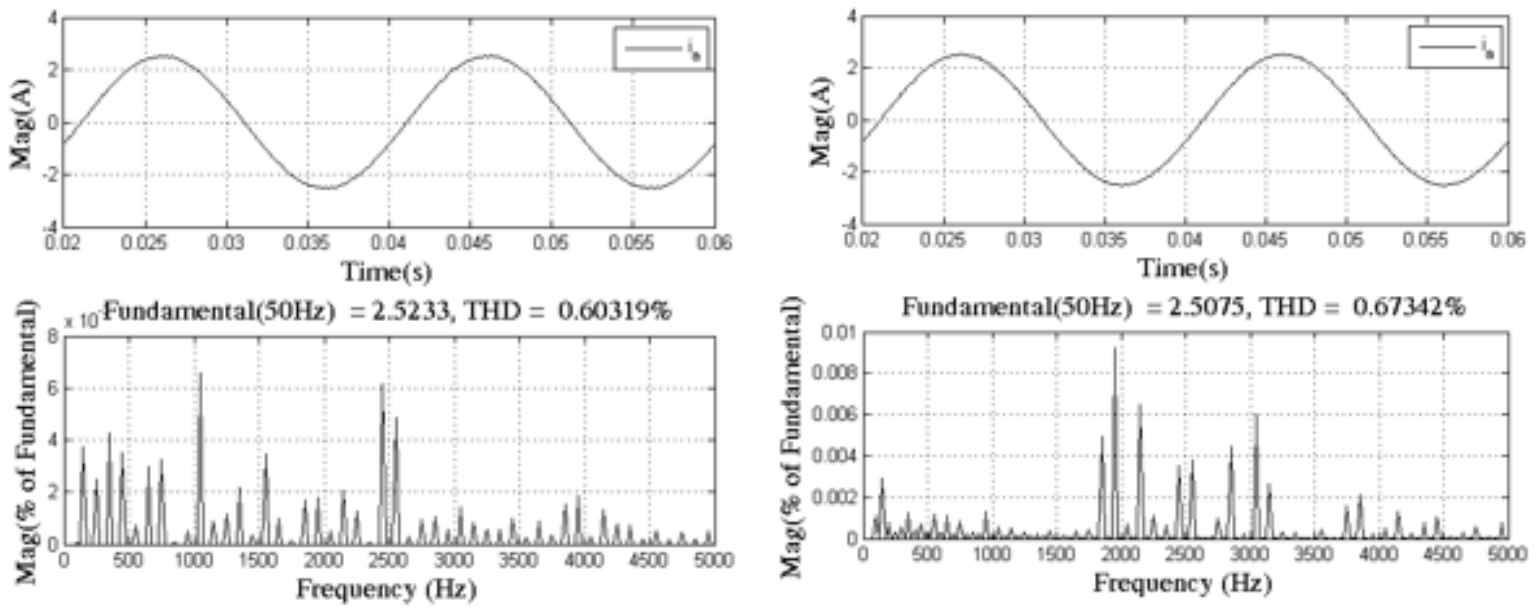

(a) PSK modulation strategy

(b) APOD
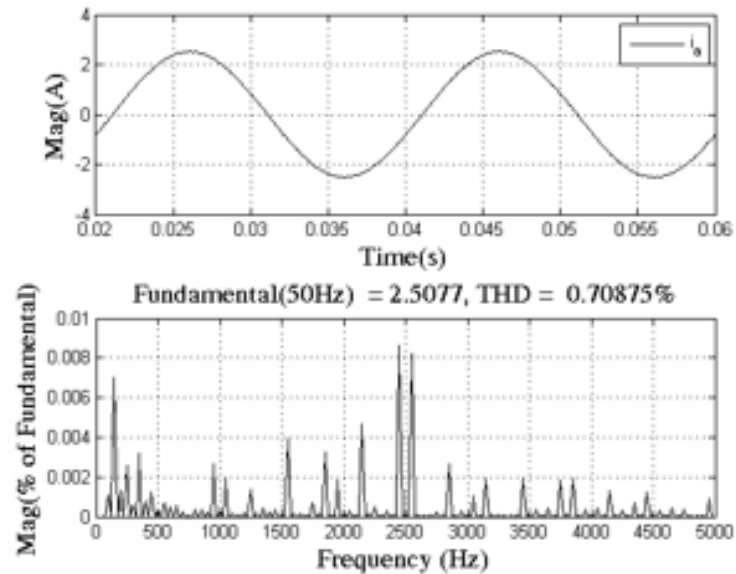

(c) POD

Figure 13. Top Trace: Phase Current $i_{a}$, Bottom Trace: THD of phase current $i_{a}$ for $E_{m}=1.0$ 

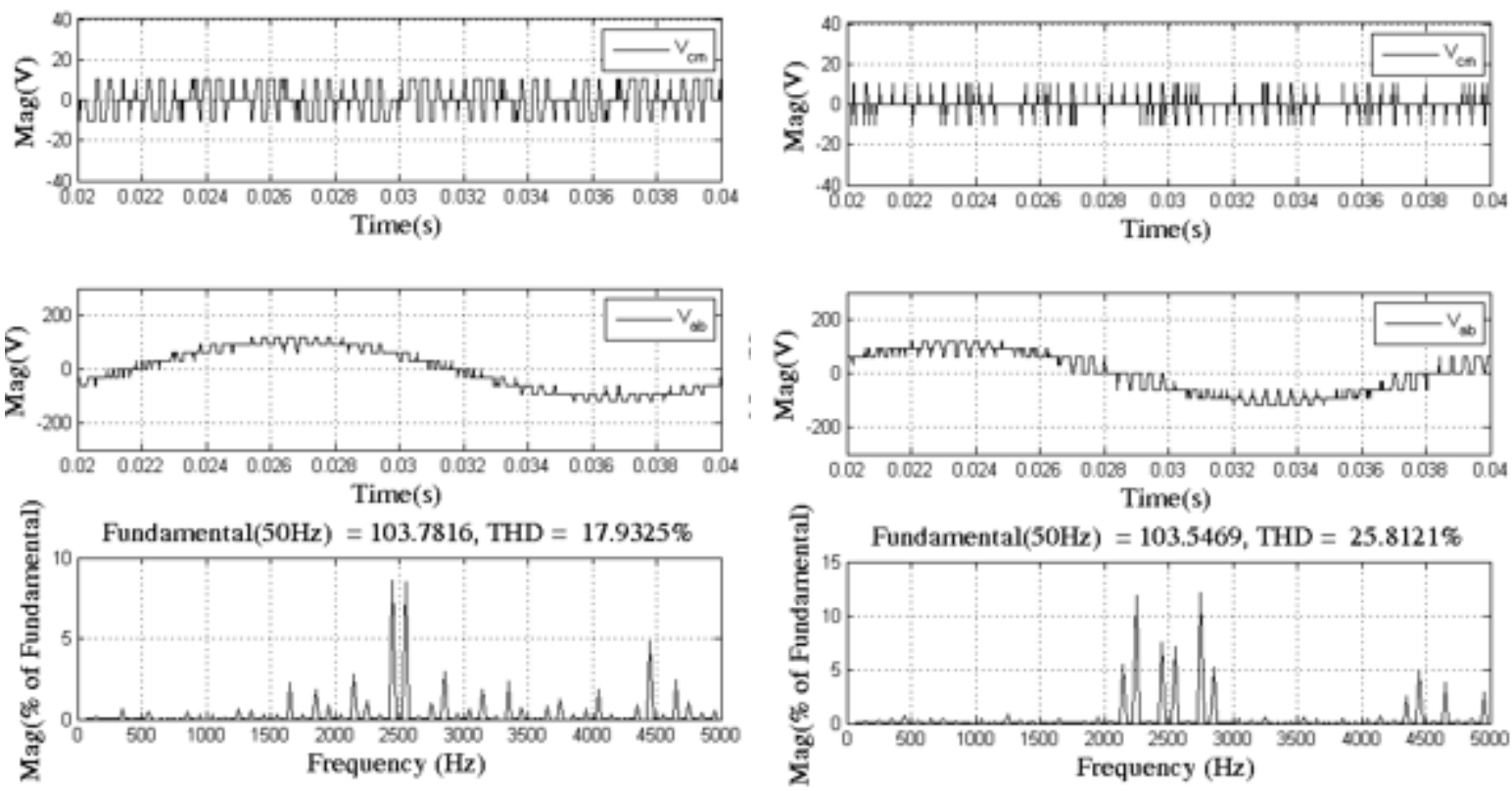

(a) PSK modulation strategy

(b) APOD
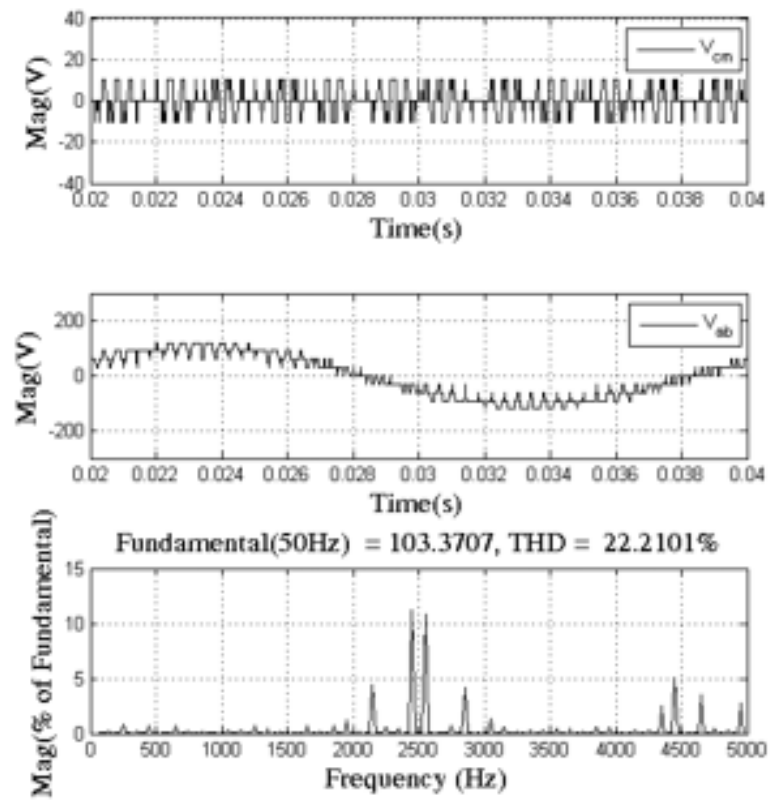

(c) POD

Figure 14. Top Trace: CMV waveform, Middle Trace: Line voltage $\mathrm{V}_{\mathrm{ab}}$, Bottom Trace: THD of line voltage $\mathrm{V}_{\mathrm{ab}}$ for $\mathrm{E}_{\mathrm{m}}=0.5$

Similarly, in case $E_{m}=0.5$, the line voltage THD value of the PSK in Figure 14 (a), as $17.9 \%$, is the smallest compared with those of the APOD and POD in Figures 14(b) and 14(c) as 25.8\% and 22.2\% correspondingly. As a result, the PSK phase current THD, as $0.9 \%$ in Figure 15(a), is the lowest compared with those of the APOD and POD as $1.34 \%$ and $1.2 \%$ in Figures 15(b) and 15(c) respectively.

For $E_{m}=0.2$, the results in Figure 16 have also showed the voltage THD value of the PSK, as $48.1 \%$, is lower than those of the APOD and POD as $69.1 \%$ and $69.7 \%$ respectively. The results in Figure 17 also showed the current THD of the PSK is as $2.4 \%$, lower than those of the others as $3.8 \%$ and $3.7 \%$ respectively. The voltage and current THD values of the three methods according to the magnitude of $\mathrm{E}_{\mathrm{m}}$ are also shown in Figure 18. Especially, the line voltage weighted THD factor (WTHD) of the PSK method in the bottom trace of Figure 18 has the same shape as the current THD in the middle trace of Figure 18. This means that the PSK method offers independence from the load parameters R-L [29].

Reduction of common mode voltage for cascaded multilevel inverters using phase... (Vinh-Quan Nguyen) 

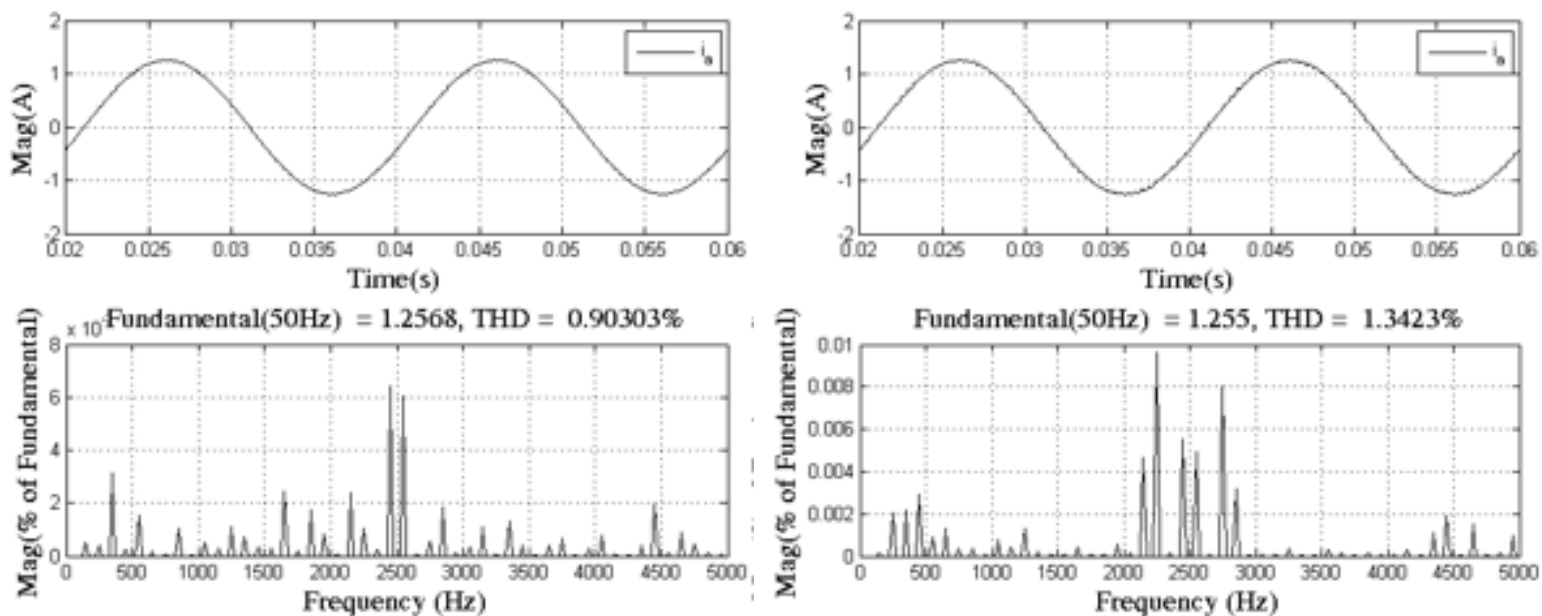

(a) PSK modulation strategy

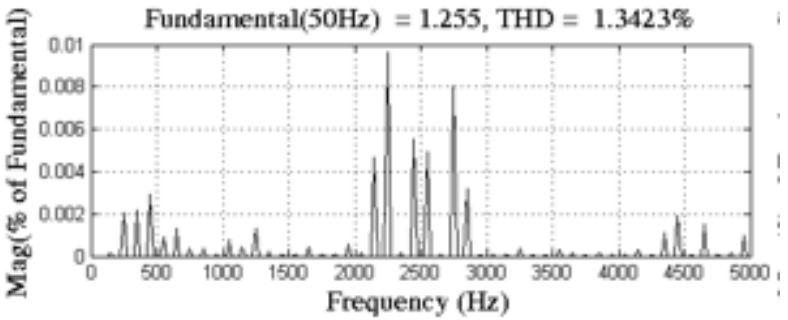

(b) APOD
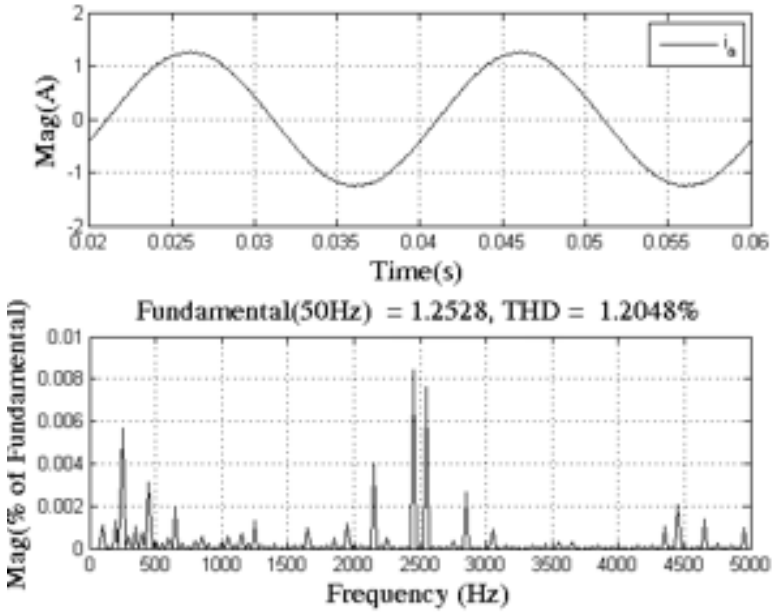

(c) POD

Figure 15. Top Trace: Phase Current $i_{a}$, Bottom Trace: THD of phase current $i_{a}$ for $E_{m}=0.5$
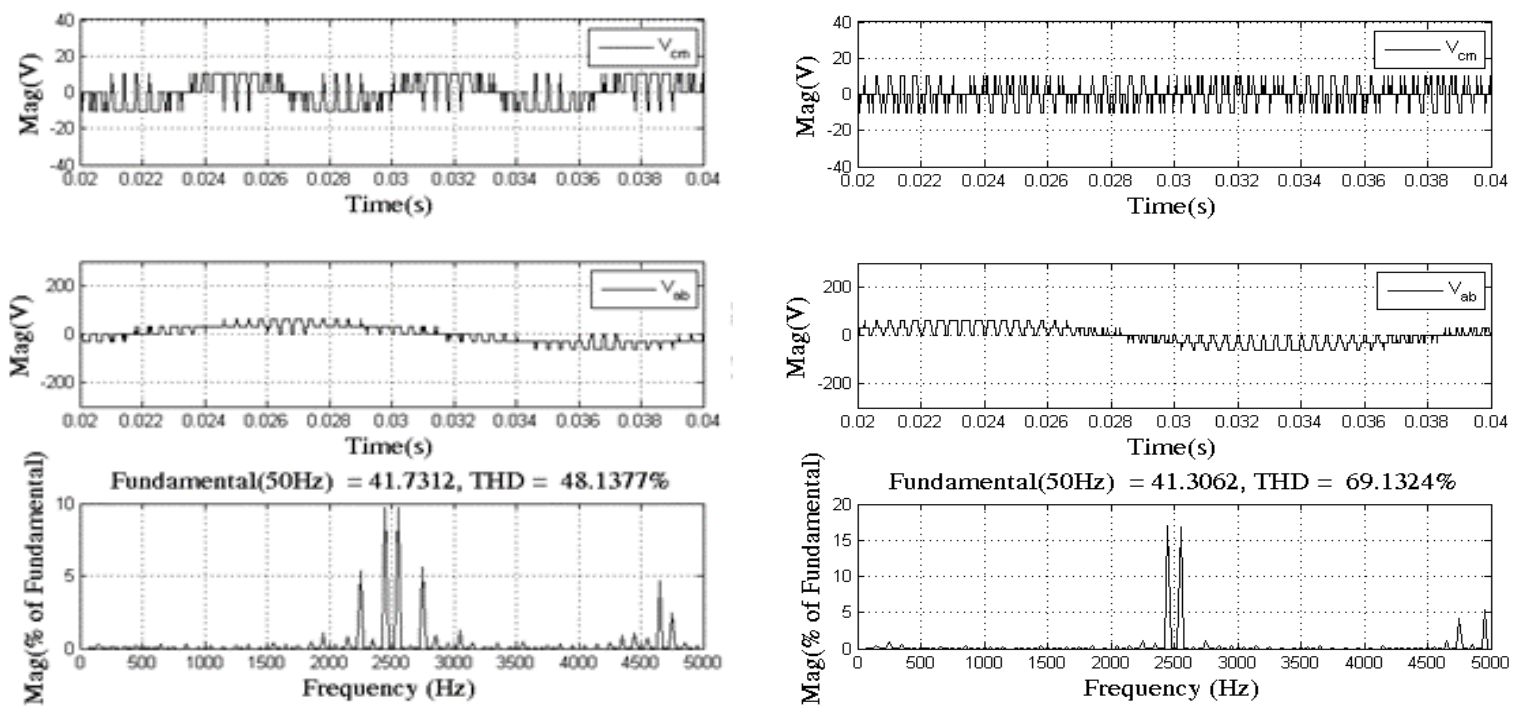

(a) PSK modulation strategy

(b) APOD 

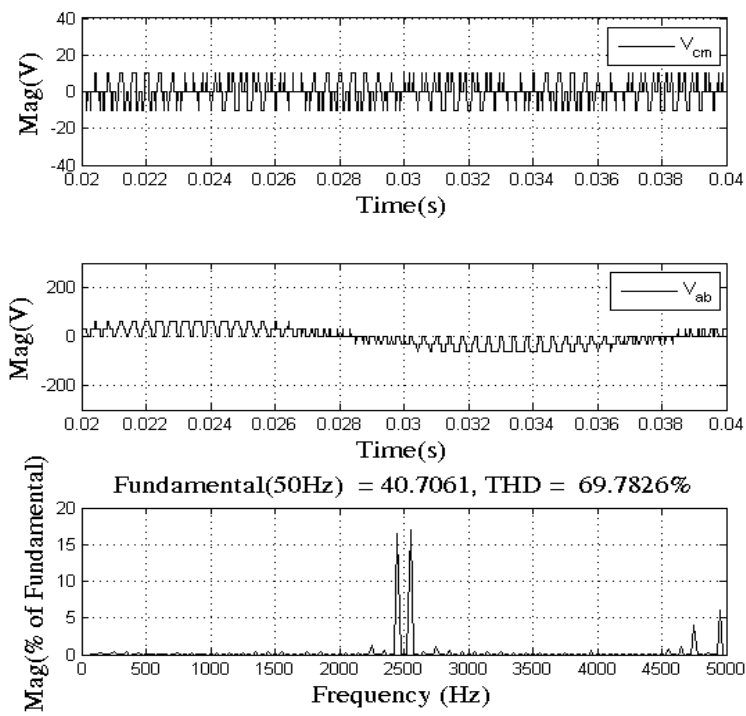

(c) POD

Figure 16. Top Trace: CMV waveform, Middle Trace: Line voltage $\mathrm{V}_{\mathrm{ab}}$, Bottom Trace: THD of line voltage $\mathrm{V}_{\mathrm{ab}}$ for $\mathrm{E}_{\mathrm{m}}=0.2$
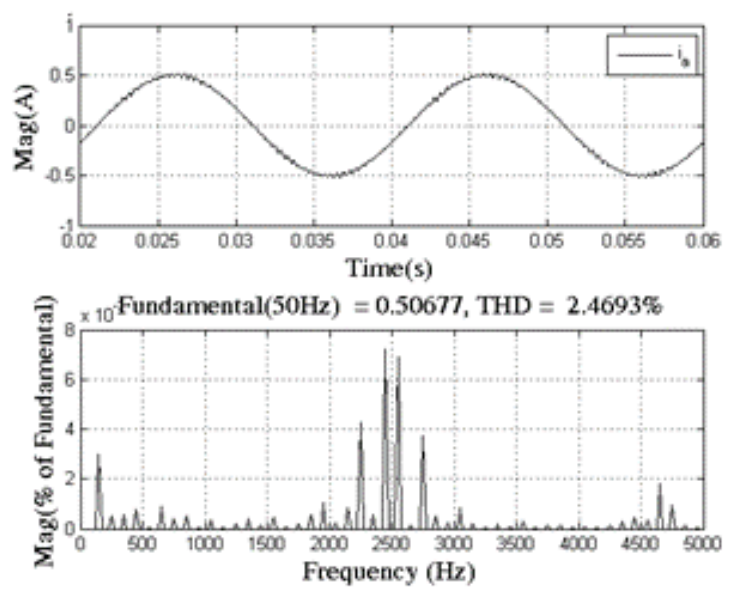

(a) PSK modulation strategy
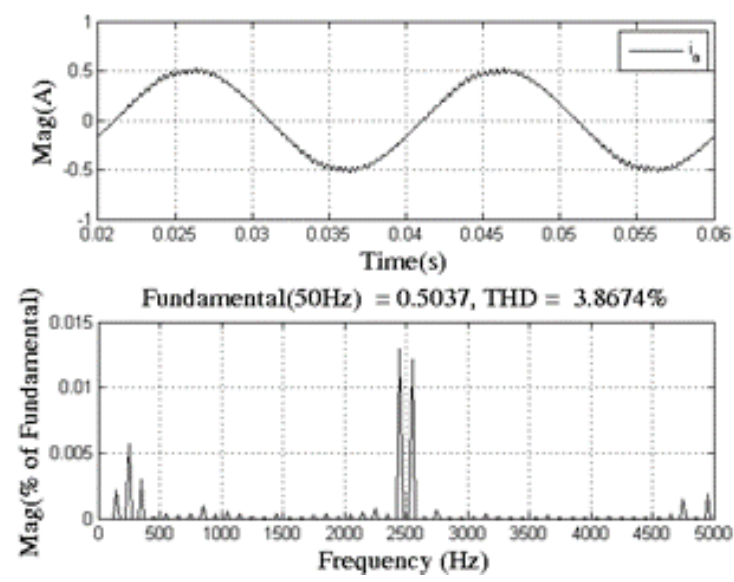

(b) APOD
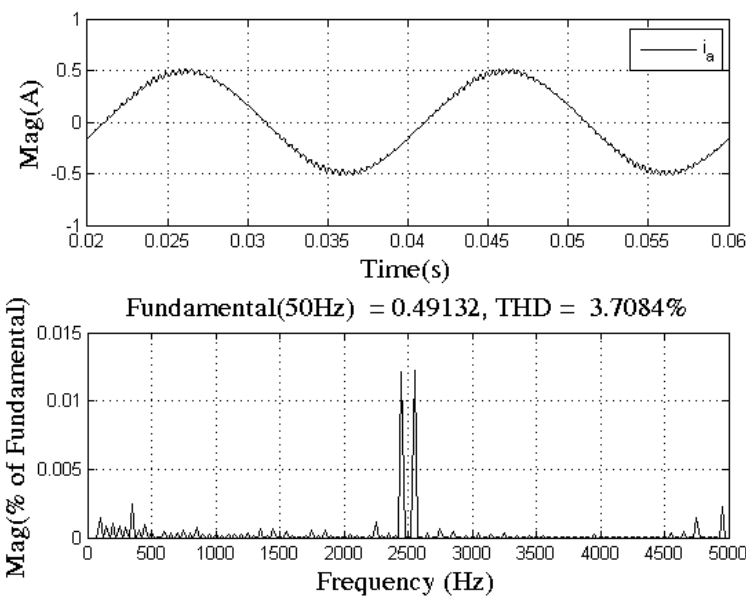

(c) POD

Figure 17. Top Trace: Phase Current $i_{a}$, Bottom Trace: THD of phase current $i_{a}$ for $E_{m}=0.2$ 

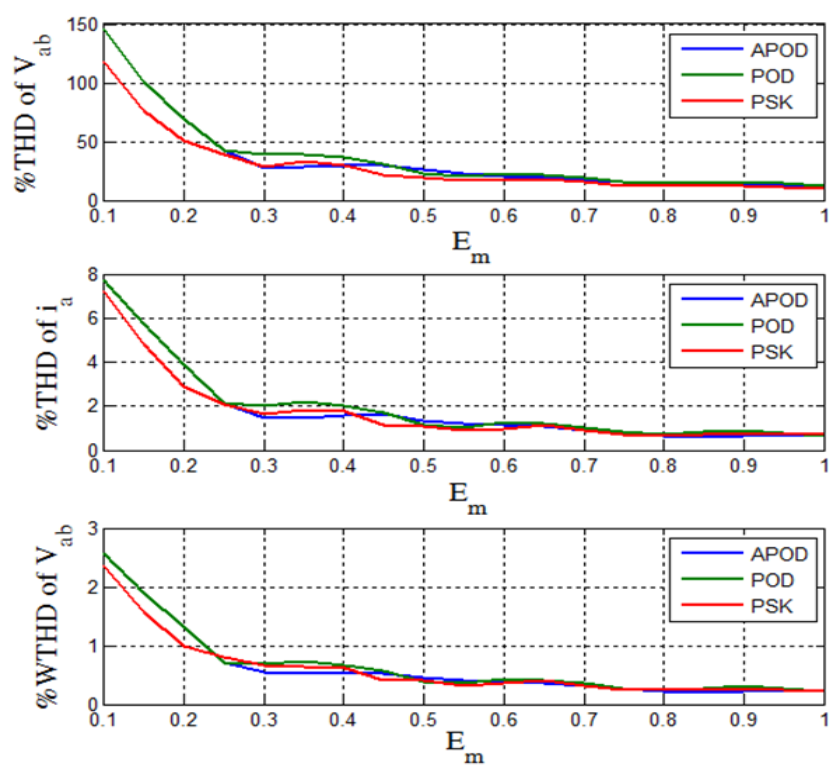

Figure 18. THD values versus $\mathrm{E}_{\mathrm{m}}$

Moreover, in every fundamental period, the number of IGBT switching commutations in Figure 19 for each phase of the PSK modulation method is low significantly compared with those of the APOD and POD methods when using the proposed strategy in Figure 10. This will contribute to decreasing the switching loss of inverters.

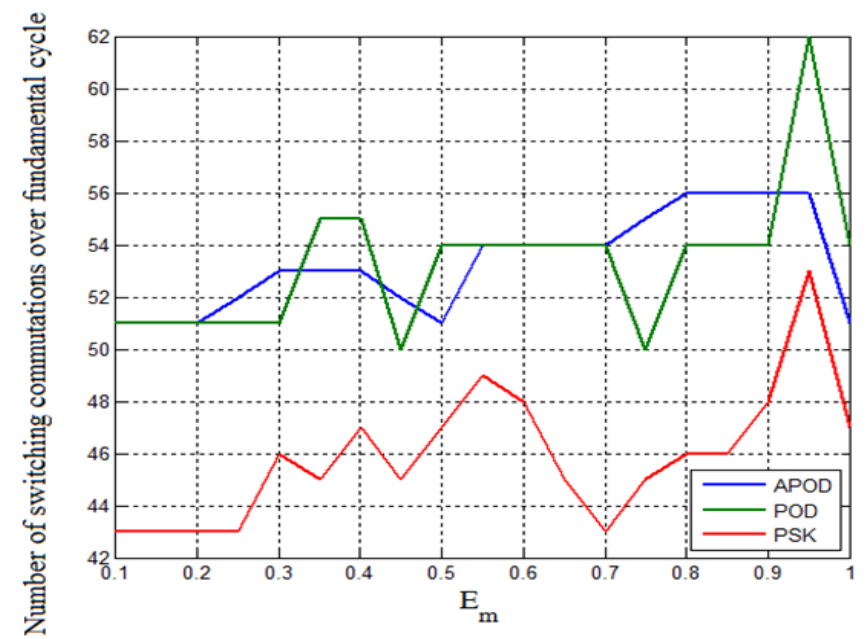

Figure 19. The number of switching commutations versus $\mathrm{E}_{\mathrm{m}}$

\subsection{Experiment results}

The model used for experiment in this paper has used an F28379D DSP kit and a cascaded 9-level inverter system. The experiment results of the PSK method are shown in Figure 20, Figure 21, Figure 22. The THD comparison of the PSK, APOD, and POD methods is shown in Figure 23. The common mode voltage for $E_{m}=1$ in the top trace of Figure 20 (a) is still $\pm 10 \mathrm{~V}$. However, the center of the CMV is not zero any more. Because the voltages of the DC sources in the fact are not the same as $30 \mathrm{~V}$. This also proves that the PSK method is true for the unbalanced DC sources. The line voltage THD is $12.6 \%$ and the phase current THD is $1.9 \%$. These experiment values are slightly higher than those of the simulation results in Figure 12 and Figure 13. However, the experiment values of the APOD and POD are also slightly higher than those of the simulation results respectively due to the hardware parameters slightly different from the simulation ones. 

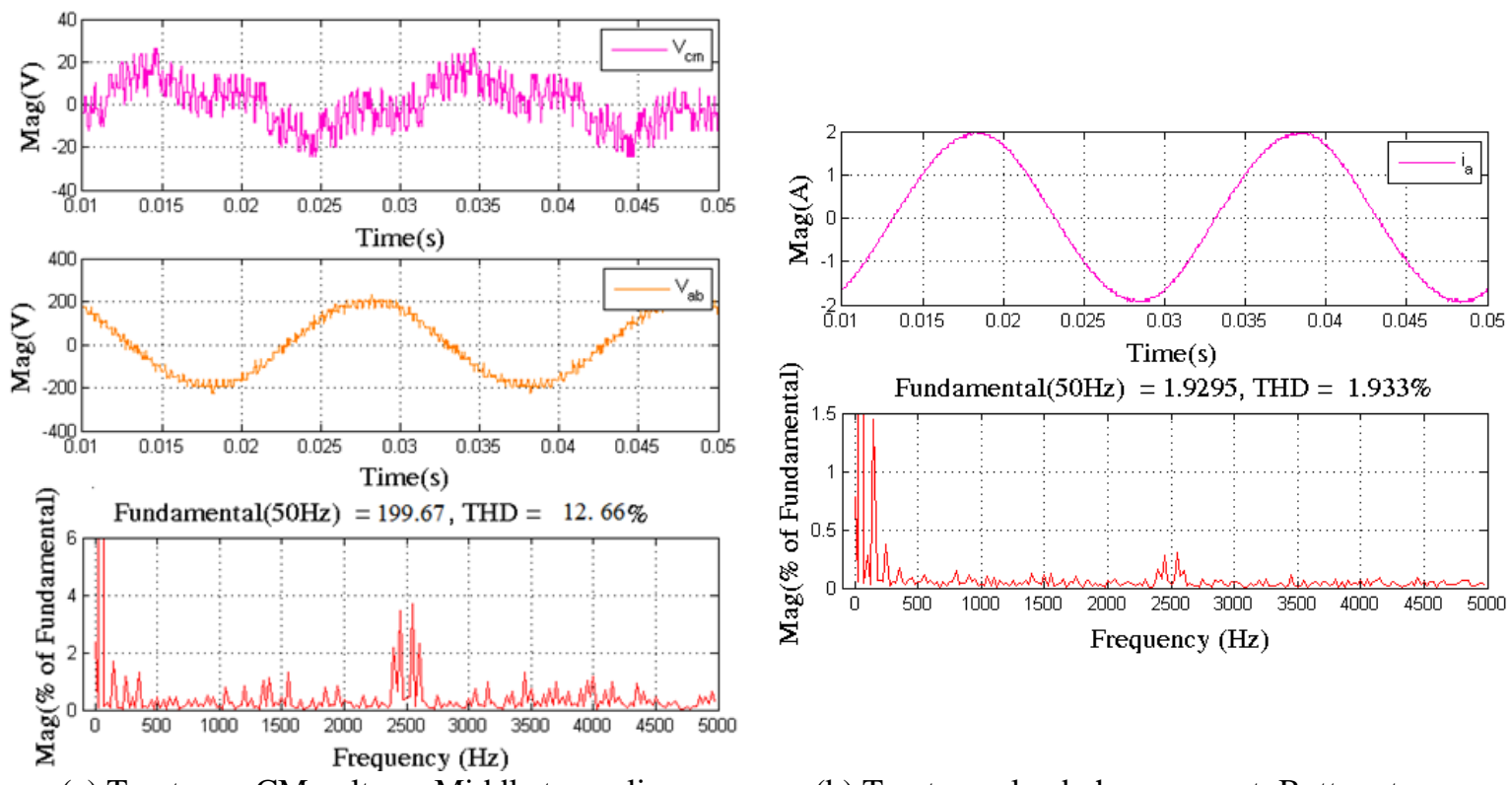

(a) Top trace: $\mathrm{CM}$ voltage, Middle trace: line voltage, Bottom trace: line voltage frequency spectrum

(b) Top trace: load phase current, Bottom trace: phase current frequency spectrum

Figure 20. The line voltage and phase current frequency spectra for $E_{m}=1$
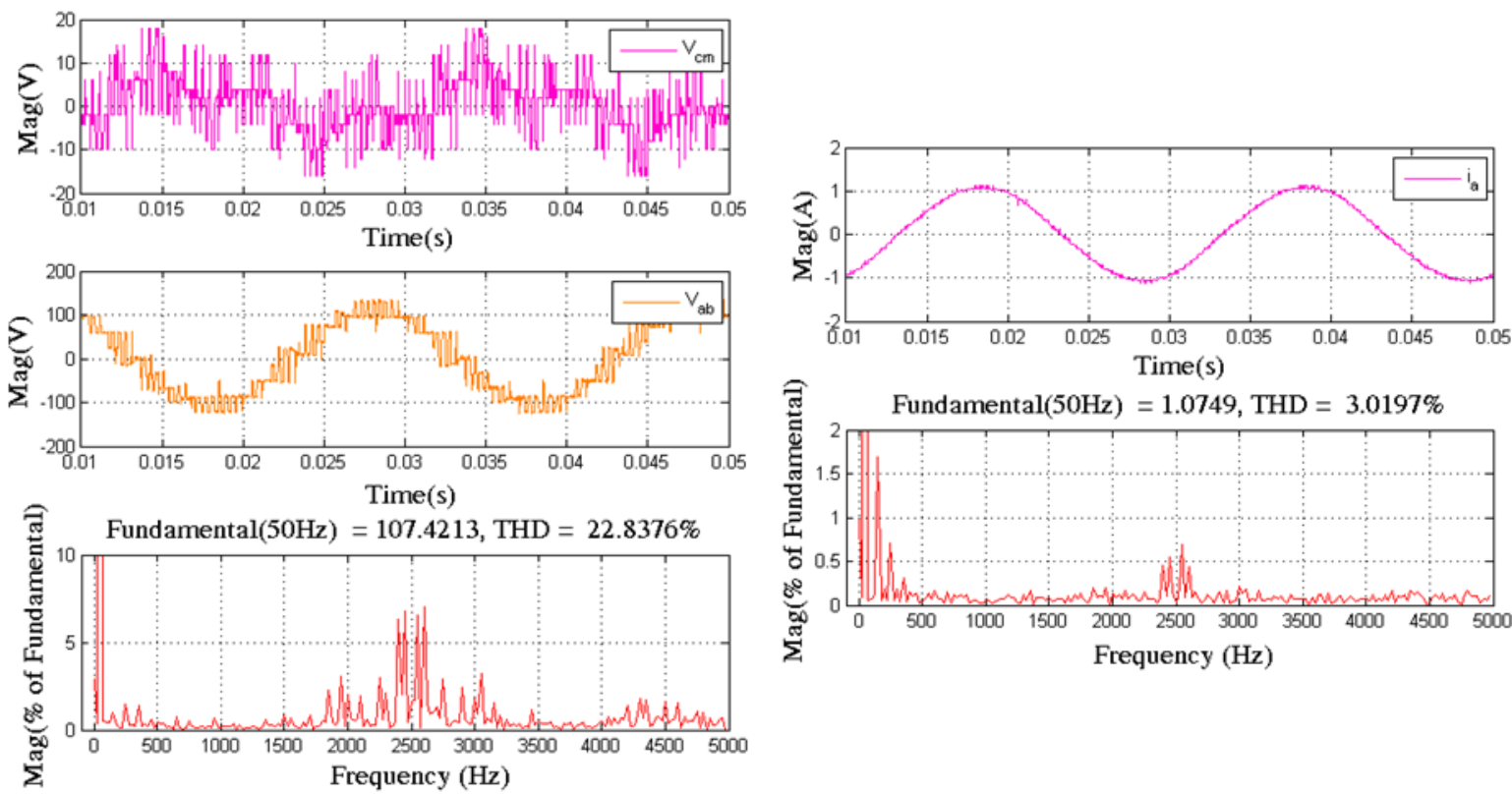

(a) Top trace: CM voltage, Middle trace: line voltage, Bottom trace: line voltage frequency spectrum

(b) Top trace: load phase current, Bottom trace: phase current frequency spectrum

Figure 21. The line voltage and phase current frequency spectra for $\mathrm{E}_{\mathrm{m}}=0.5$

Similarly, for $\mathrm{E}_{\mathrm{m}}=0.5$, the line voltage THD is $22.8 \%$ in Figure 21(a) and the phase current THD is as $3 \%$ in Figure $21(\mathrm{~b})$. When $\mathrm{E}_{\mathrm{m}}=0.2$, the experiment results showed the line voltage and phase current THD values are $58.7 \%$ and $6.7 \%$ in Figure 22 respectively. 

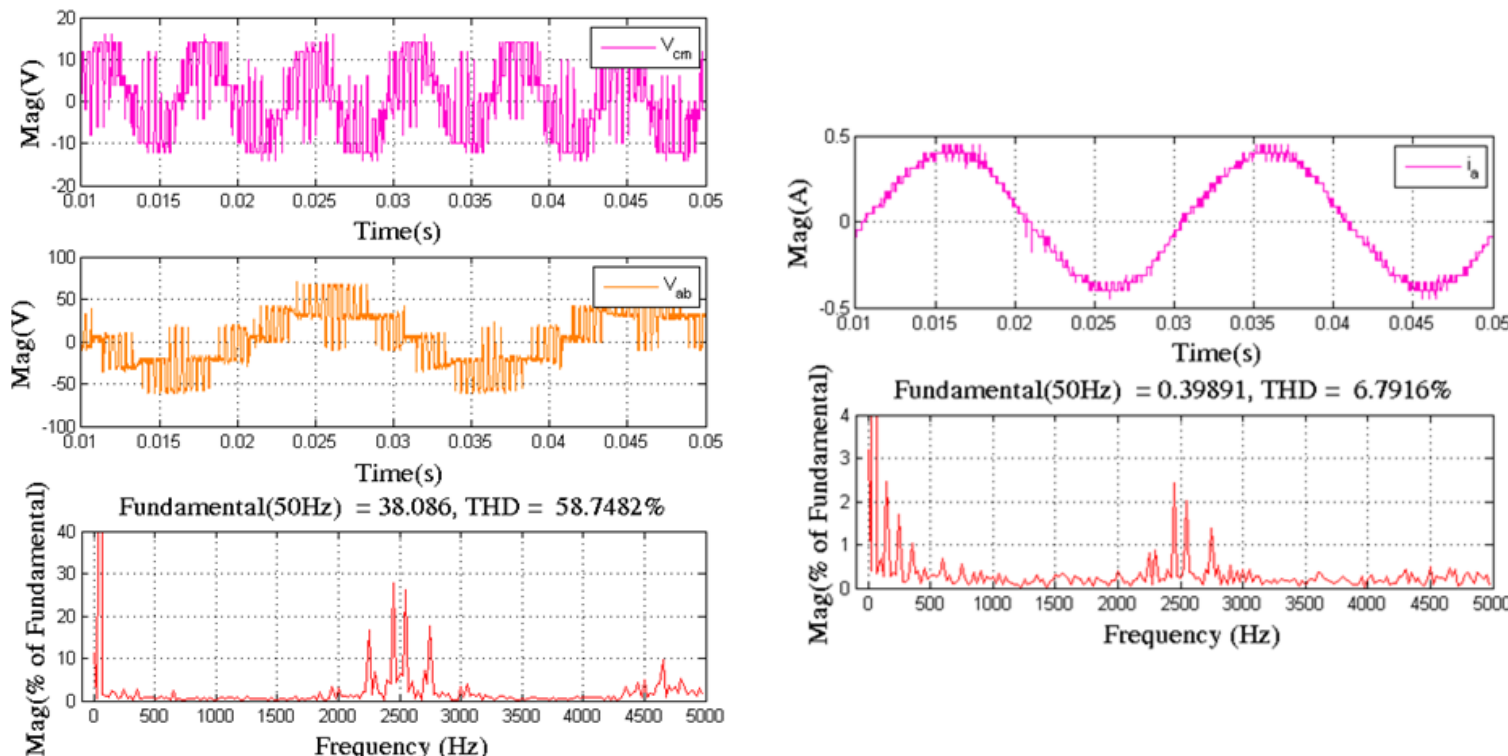

(a) Top trace: CM voltage, Middle trace: line voltage, Bottom trace: line voltage frequency spectrum

(b) Top trace: load phase current, Bottom trace: phase current frequency spectrum

Figure 22. The line voltage and phase current frequency spectra for $E_{m}=0.2$

In addition, the experiment THD results in Figure 23 have also validated the performance of the PSK method equivalent to the APOD method.
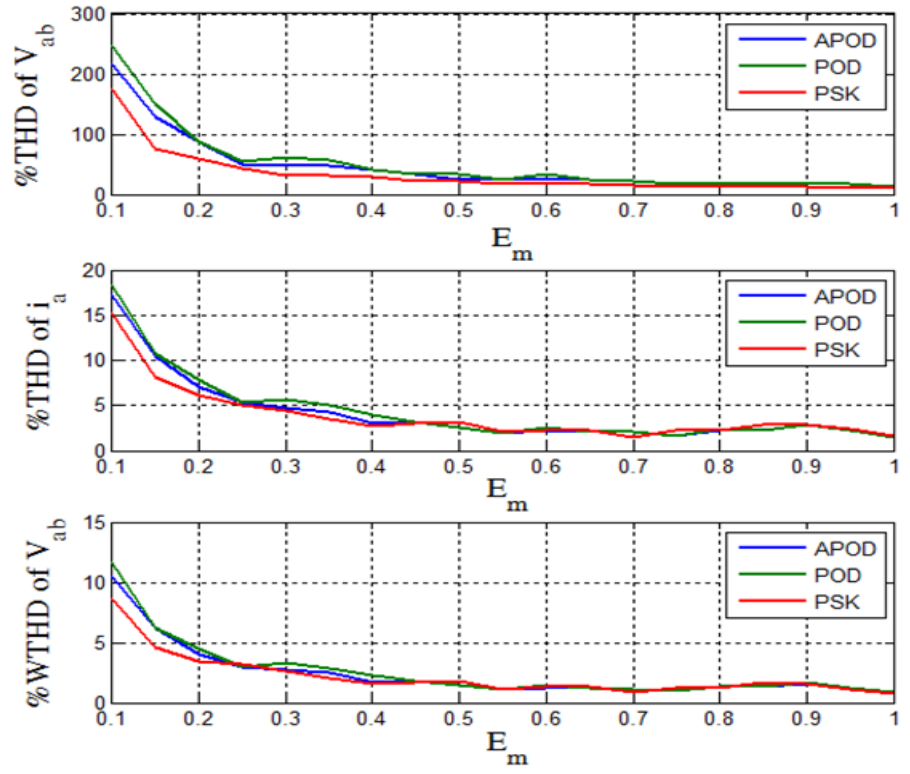

Figure 23. THD values versus $\mathrm{E}_{\mathrm{m}}$ for experiment

\section{CONCLUSION}

This paper presented a method for decreasing the common mode voltage of cascaded multilevel inverters using the phase shift keying technique to modulate the phase of carrier waves. This technique also helps the cascaded multilevel inverters reduce the number of switching commutations of IGBTs when using the proposed strategy. Then, it reduces switching loss of inverters. In addition, the output voltage harmonics 
are also significantly suppressed. The weighted total harmonic distortion factor (WTHD) is also considered to prove the undependence from the load parameters of the proposed method. The simulation and experiment results on the cascaded 9-level 3-phase inverter system have confirmed the performance of the proposed method compared with those of the APOD and POD using unmodulated carrier waves.

\section{ACKNOWLEDGEMENTS}

This work belongs to the project in 2021 funded by Ho Chi Minh City University of Technology and Education, Vietnam.

\section{REFERENCES}

[1] M. M. Hasan, A. Abu-Siada, S. M. Islam, and M. S. A. Dahidah, "A New Cascaded Multilevel Inverter Topology with Galvanic Isolation,” IEEE Trans. Ind. Appl., vol. 54, no. 4, pp. 3463-3472, 2018.

[2] M. D. Siddique, S. Mekhilef, N. M. Shah, and M. A. Memon, "Optimal Design of a New Cascaded Multilevel Inverter Topology With Reduced Switch Count," IEEE Access, vol. 7, pp. 24498-24510, 2019.

[3] J. Zeng et al., "Dynamic space vector based discontinuous PWM for three-level inverters," Int. J. Electr. Power Energy Syst., vol. 117, 2020.

[4] M. Sujatha and A. K. Parvathy, "Improved reliable multilevel inverter for renewable energy systems," Indones. J. Electr. Eng. Comput. Sci., vol. 14, no. 3, pp. 1141-1147, 2019.

[5] T. T. Nguyen, "The multilevel inverter with clamped-diode," Indones. J. Electr. Eng. Comput. Sci., vol. 14, no. 3, pp. 1189-1195, 2019.

[6] M. Rasheed, R. Omar, M. Sulaiman, and W. A. Halim, "Particle swarm optimisation (PSO) algorithm with reduced numberof switches in multilevel inverter (MLI)," Indones. J. Electr. Eng. Comput. Sci., vol. 14, no. 3, pp. 1114$1124,2019$.

[7] D. Selvabharathi, et al., "Simulation of zeta converter based 3-level NPC inverter with PV system," Indones. J. Electr. Eng. Comput. Sci., vol. 12, no. 1, pp. 1-6, 2018.

[8] J. R. Rahul and K. Annamalai, "Multistring seven-level quasi Z-source based asymmetrical inverter," Indones. J. Electr. Eng. Comput. Sci., vol. 15, no. 1, pp. 88-94, 2019.

[9] M. Abbes, J. Belhadj, and A. Ben Abdelghani Bennani, "Design and control of a direct drive wind turbine equipped with multilevel converters," Renew. Energy, vol. 35, no. 5, pp. 936-945, 2010.

[10] N. A. Rahim, J. Selvaraj, and C. Krismadinata, "Five-level inverter with dual reference modulation technique for grid-connected PV system," Renew. Energy, vol. 35, no. 3, pp. 712-720, 2010.

[11] A. K. Panda and Y. Suresh, "Research on cascade multilevel inverter with single DC source by using three-phase transformers," Int. J. Electr. Power Energy Syst., vol. 40, no. 1, pp. 9-20, 2012.

[12] H. J. Kim, H. D. Lee, and S. K. Sul, "A new PWM strategy for common-mode voltage reduction in neutral-pointclamped inverter-fed ac motor drives," IEEE Trans. Ind. Appl., vol. 37, no. 6, pp. 1840-1845, 2001.

[13] A. K. Gupta and A. M. Khambadkone, "A space vector modulation scheme to reduce common mode voltage for cascaded multilevel inverters," IEEE Trans. Power Electron., vol. 22, no. 5, pp. 1672-1681, 2007.

[14] H. Zhang, A. Von Jouanne, S. Dai, A. K. Wallace, and F. Wang, "Multilevel inverter modulation schemes to eliminate common-mode voltages," IEEE Trans. Ind. Appl., vol. 36, no. 6, pp. 1645-1653, 2000.

[15] P. C. Loh, D. G. Holmes, Y. Fukuta, and T. A. Lipo, "Reduced common-mode modulation strategies for cascaded multilevel inverters," IEEE Trans. Ind. Appl., vol. 39, no. 5, pp. 1386-1395, 2003.

[16] M. Rasheed, R. Omar, M. Sulaiman, and W. A. Halim, "A modified cascaded h-bridge multilevel inverter based on particle swarm optimisation ( PSO ) technique,” Indones. J. Electr. Eng. Comput. Sci., vol. 16, no. 1, pp. 41-51, 2019.

[17] J. Rodríguez, J. Pontt, P. Correa, P. Cortés, and C. Silva, "A new modulation method to reduce common-mode voltages in multilevel inverters," IEEE Trans. Ind. Electron., vol. 51, no. 4, pp. 834-839, 2004.

[18] P. C. Loh, D. G. Holmes, Y. Fukuta, and T. A. Lipo, "A reduced common mode hysteresis current regulation strategy for multilevel inverters," IEEE Trans. Power Electron., vol. 19, no. 1, pp. 192-200, 2004.

[19] A. M. Hava and E. Ün, "Performance analysis of reduced common-mode voltage PWM methods and comparison with standard PWM methods for three-phase voltage-source inverters," IEEE Trans. Power Electron., vol. 24 , no. 1, pp. 241-252, 2009.

[20] V. Naumanen, J. Korhonen, J. Luukko, and P. Silventoinen, "Multilevel inverter modulation method to reduce common-mode voltage and overvoltage at the motor terminals," in 2010 IEEE 26th Convention of Electrical and Electronics Engineers in Israel, IEEEI 2010, pp. 296-300, 2010.

[21] T. S. Yin, P. Ehkan, S. V. Siew, L. C. Yuen, and M. N. M. Warip, "FPGA implementation of real time string colour detection," Indones. J. Electr. Eng. Comput. Sci., vol. 6, no. 1, pp. 139-147, 2017.

[22] I. H. Shanono, N. R. H. Abdullah, and A. Muhammad, "Five-level single source voltage converter controlled using selective harmonic elimination," Indones. J. Electr. Eng. Comput. Sci., vol. 12, no. 3, pp. 924-932, 2018.

[23] Suroso, D. T. Nugroho, A. N. Azis, and T. Noguchi, "Simplified five-level voltage source inverter with levelphase-shifted carriers based modulation technique," Indones. J. Electr. Eng. Comput. Sci., vol. 13, no. 2, pp. 461468, 2019.

[24] J. D. Tan, S. P. Koh, S. K. Tiong, K. Ali, and A. Abdalla, "Fuzzy logic enhanced direct torque control with space vector modulation,” Indones. J. Electr. Eng. Comput. Sci., vol. 11, no. 2, pp. 704-710, 2018.

\footnotetext{
Reduction of common mode voltage for cascaded multilevel inverters using phase ... (Vinh-Quan Nguyen)
} 
[25] M. Oner, "On the Classification of Binary Space Shift Keying Modulation," IEEE Commun. Lett., vol. 22, no. 8, pp. 1584-1587, 2018

[26] L. Xie and Q. Wan, "Automatic Modulation Recognition for Phase Shift Keying Signals with Compressive Measurements," IEEE Wirel. Commun. Lett., vol. 7, no. 2, pp. 194-197, 2018.

[27] B. Yan et al., "EDFA Anti-Irradiation Schemes for Inter-Satellite Optical DPSK Communication Systems," IEEE Photonics J., vol. 11, no. 3, pp. 1-11, 2019.

[28] J. Boiko and O. Eromenko, "Signal processing in telecommunications with forward correction of errors," Indones. J. Electr. Eng. Comput. Sci., vol. 11, no. 3, pp. 868-877, 2018.

[29] G. Narayanan and V. T. Ranganathan, "Analytical evaluation of harmonic distortion in PWM AC drives using the notion of stator flux ripple," IEEE Trans. Power Electron., vol. 20, no. 2, pp. 466-474, 2005.

\section{BIOGRAPHIES OF AUTHORS}

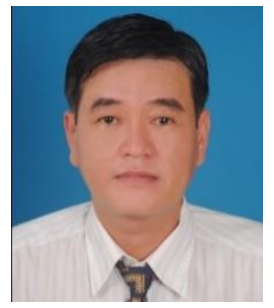

Vinh-Quan Nguyen was born in Vietnam, in 1963. He received his M. E. degree in Automation from HCM city University of Technology, VNU-HCMC, Vietnam, in 2011. He had also completed his Ph. D. degree in Power systems from HCM city University of Technology, VNUHCMC, Vietnam, in 2020. He is currently working as a lecture in Faculty of Electrical and Electronics Engineering, HCM city University of Technology and Education. His research interests are circuit design, power electronics control, and embedded systems.

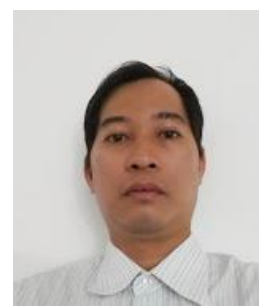

Quang-Tho Tran received his M. E. degree in Electrical Engineering from HCM city University of Technology, VNU-HCMC, Vietnam, in 2003; and his Ph. D. degree in Electrical Engineering from HCM-UTE, Vietnam. He is currently working as a lecture in Faculty of Electrical and Electronics Engineering, HCM city University of Technology and Education. His research interests include electric drives, DC-AC inverters, DC-DC converters, and renewable energy conversion. 